\title{
Dynamicity of Plant-Insect Interaction, Defense Communism and Key-Prospects
}

\author{
Javed MW1*, Ahmad JN1, Shahzad MK², Hussain M³ , Ahmad SJN4, \\ Ashraf $\mathbf{M}^{5}$, Imran $\mathbf{M}^{2}$, Mushtaq N6, Hafeez A , Aslam A $^{7}$ and Jafir $\mathbf{M}^{1}$ \\ 1Integrated Genomics, Cellular, Developmental and Biotechnology Laboratory, \\ Department of Entomology, University of Agriculture, Faisalabad, Pakistan \\ Review Article \\ Volume 3 Issue 7 \\ Received Date: August 15, 2018 \\ Published Date: August 31, 2018 \\ ${ }^{2}$ Department of Plant Protection, Punjab, Pakistan \\ ${ }^{3}$ Department of Agronomy, Bahauddin Zakariya University Multan, Pakistan \\ ${ }^{4}$ Plant Stress Physiology and Molecular Biology Laboratory, Department of Botany, University of Agriculture, Faisalabad, \\ Pakistan \\ ${ }^{5}$ Department of Plant Protection Agricultural Research Institute Sariab Road Quetta, Pakistan \\ 6Insect Biodiversity and Systematics Laboratory, Department of Entomology, University of Agriculture, Faisalabad, \\ Pakistan \\ ${ }^{7}$ Beekeeping and Hill Fruit Pests Research Station, Rawalpindi, Pakistan
}

*Corresponding author: Muhammad Wajid Javed, Integrated Genomics, Cellular, Developmental and Biotechnology Laboratory, Department of Entomology, University of Agriculture, Faisalabad, Pakistan, Tel: +92 313 7070047; Email: muhammadwajidjaved@gmail.com

\section{Abstract}

Both insects and plants have dynamicity of interaction, defense communism and key-prospects for their own benefits, survival and longtime sustainable dependencies with minimal foreign intrusions. Dynamics of their interactions are appropriate with their described co-existence and respective gain/loss in varied cropping schemes since ancient times. These interactions may be harmful or beneficial with special focus to cultivated crops in agriculture. With respect to herbivorous insects, plants are not only depending on external features but also utilizing a number of defensive genes like PR-pathogenesis related proteins, PIN-proteinase inhibitors, LOX-lipoxygenase, PAL-phenyl ammonia lyaseetc in induced pest resistance mechanism. In addition, of course, multiple electric signs, defense signallings/resistance connections like Jasmonic Acid/JA and/or Salicylic Acid/SA to retard the scope and expansion of uninvited enemy, are also accounted. Moreover, in this review, a concise view of key-prospects in aforementioned dynamicity have also been presented covering fundamental to applied aspects.

Keywords: Insect Plant Biological Connections; Signallings; Genes; Mutualism; Ecology 


\section{Open Access Journal of Agricultural Research}

\section{Insect Plant Interrelations}

Plants are among the abundant proliferating members of kingdom Plantae with 300000 species specific individuals raided by a number of myriad insects and other organisms [1]. In the similar way, insect number reached with about 6 million, with approximations of 3 millions falling in the category of plant feeders. Pathogens must have the same diverse natures though not well characteristically valued but their damaging constitution to plants cannot be neglected [2].

\section{Plants Sensation and Perception of Interactions}

Interactions of plants with reference to herbivory must be referenced for sustainable pest supervisions. Plants have developed a highly efficacious system for sensations and perceptions of signals of both beneficial and damaging insects with citations to their effects on plants (Figure 1). This systematics compromises a good mechanical orientation and chemo-based receptivity [3].

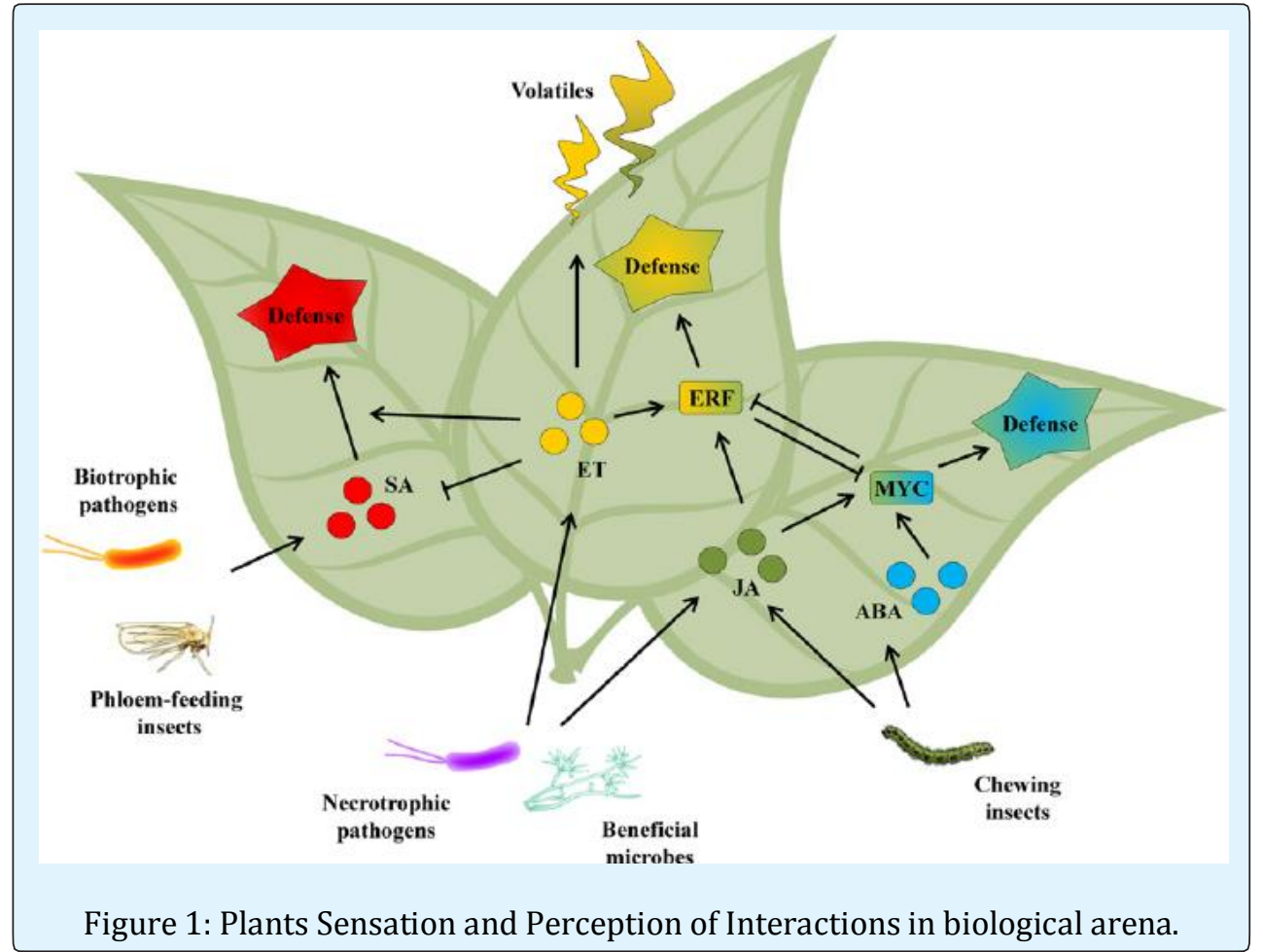

\section{Electrical Sign and Plant Interactions}

There are different plant signallings post impairment of insects with contributions of electrical signals involved in their reactions and responses. An infestation by insects signifies these electrical reasons and controls. These may be mediated by hormonal actions in plants from basic to final relations at early to late hormone productions in pest injuries [4]. Marking of new genes and biochemical defense whiteflies modulatory signalling pathways in emerging modal plant tomato Lycopersicon esculentum have also been noticed [5].

\section{Plant Connectivity and Internal Signallings}

Mechanisms of plant for insect invasion recognition may be maintained by downstream signallings and combat strategies. There are systems by which insects try to overcome the coming insects by using their internal signs [6]. This also has temporal time scale patterns with evolutionary perspectives. Insect effectors proteins sometimes modify the plant systems to favour the invasive insects with loss to the plant. Plants association with insects in environmental views, with the embodying and encompassing of other individuals taking part in this manner with variation in last and final results [7]. 


\section{Open Access Journal of Agricultural Research}

Marking of new genes and biochemical defense whiteflies modulatory signalling pathways in emerging modal plant tomato Lycopersicon esculentum have also been noticed [5]. They, usually, have a complex interactive pathways with unlimited dimensions (Figure 2).

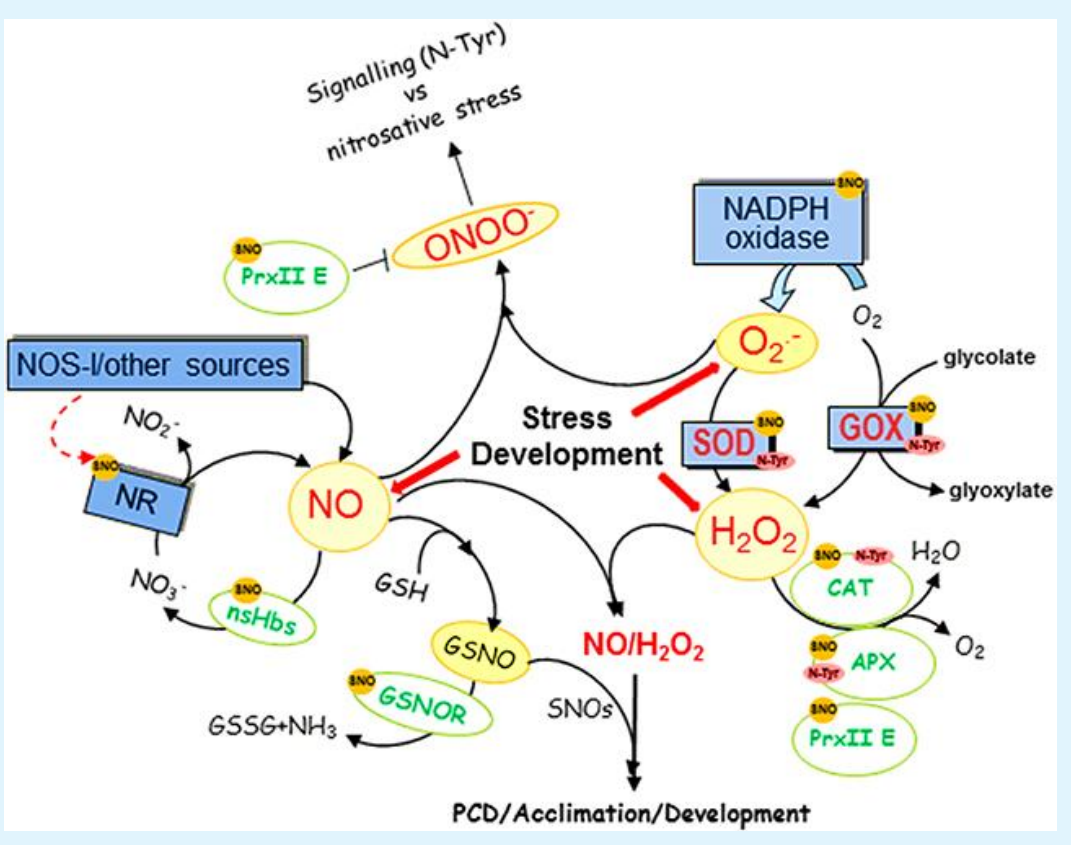

Figure 2: Complex interactive pathways with unlimited and intricate dimensions.

\section{Plants Impact on Insect Communism and Dynamicity}

Plants can play a pivotal role via their interrelationships with insect community due to their morphological, physiological and chemical significances ultimately governed by genetic manifestations [8,9]. Plants phenotypic properties as being accompanied by the genotypic mechanisms influencing the insect community partners feeding on plant. A chemical character of tannin can largely effect insect population in tree areas. Tannins are specific kind of phenolic ingredients produced by plant species [9]. There are, several reports have been noticed describing new insect/pest records owing to variations in plantations comprising a direct plant impact on their community and dynamics [10-12].

\section{Phyto-Feeders (Insects) Impact on Plant Characters}

Insects being the one of the important and sometimes the only plant feeder individuals can also have a reciprocal impact on the plants to elicit multiple responses (Figure 3). Often by induced resistance due to phyto-feeders, induced sensitivity to attacks and also other relativities [9].

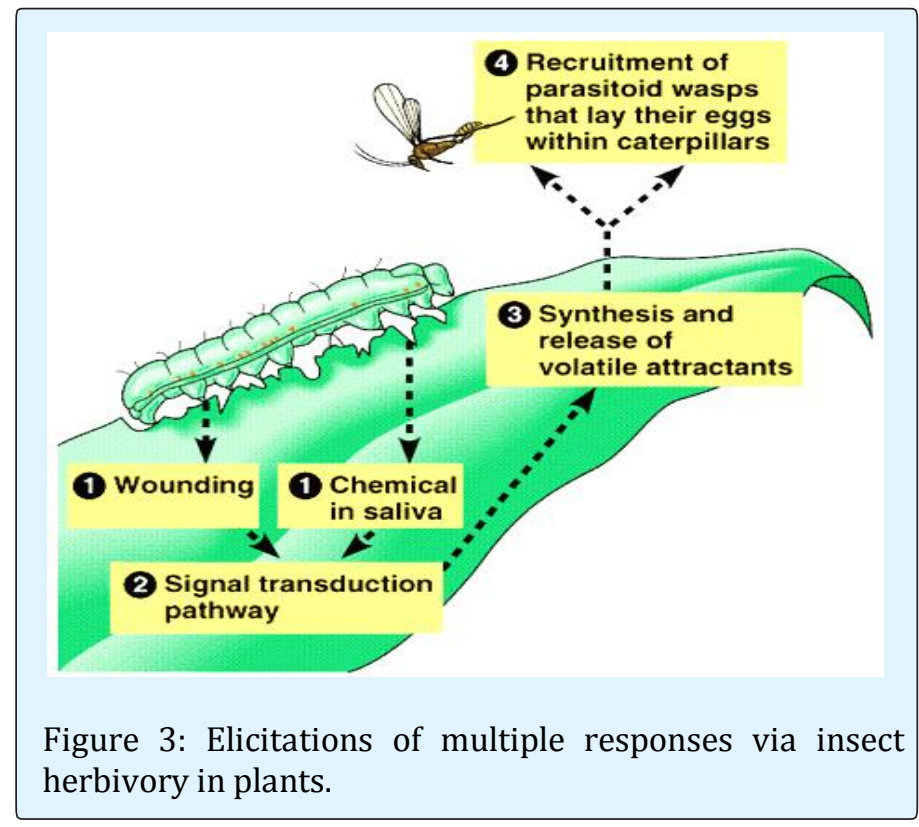




\section{Open Access Journal of Agricultural Research}

The process of induced resistance in action to herbivores mainly depends on insect feeding modes and actions, e.g., feeding of larval forms of Lepidoptera on a plant, have the ability to produce such variations in plants causing the longer larval developments of later lepidopterans damaging the same plant species $[9,13]$.

\section{Plant Insect Affiliations with Economic Perceptivity}

Insect plant relations are not only vital for molecular based tactics and systematizations but also much noticeable due to the losses that these insects have posed to crops of horticultural and agronomic views. The insects are the leading causative agents producing millions and billions of dollar losses to the agricultural sector for production and quality point of view [14].

\section{Plant Relations with Simultaneous Control of Harm and Benefit}

Plants belonging to complex families with multiple relations of insects, microbes and other individuals. Plants are focusing for varying tools for their responses to coming harmful microbes and insects with the review of beneficial microbial fauna too. Molecular and biology indulging tools are helpful in this aspect with respect to genomic and protein relying reactions in eco-dependent approaches [2]. Besides these, the impact of abiotic nutritional factors, e.g., fertilizers, on plant yield cannot be over looked [15].

Plants have in possession of betterment relations with the insects and microbes such as fungi (mycorrhizae), PGPR-the growth promotion rhizobacteria in plant soils; helping the plants improves their vigour to retard coming pest damages. By attraction of natural enemies due to volatiles produced by the plants when they are attacked by phytophagous to control herbivore feeders, and pollinators comprising honey bees fascinating by the floral ingredients, are important properties [16,17]. Insect pests screening are vital aspects to manage pest resistance in cultivated crops providing benefits to farming community [18].

\section{Insect Resistance and Plant Connections}

There may be molecular things comprised for plant interactive associativity with genetic responses. The examples is of PAD4 with characteristic of phytoalexin deficient4 for aphid resistance in plants [19]. Tomato pathogen protein genes may also be induced due to whiteflies for plant protection [20]. The expressions of insecticidal genes and henceforth proteins are evident source to exhibit plant pest/insect resistance cultivars (Figure 4).

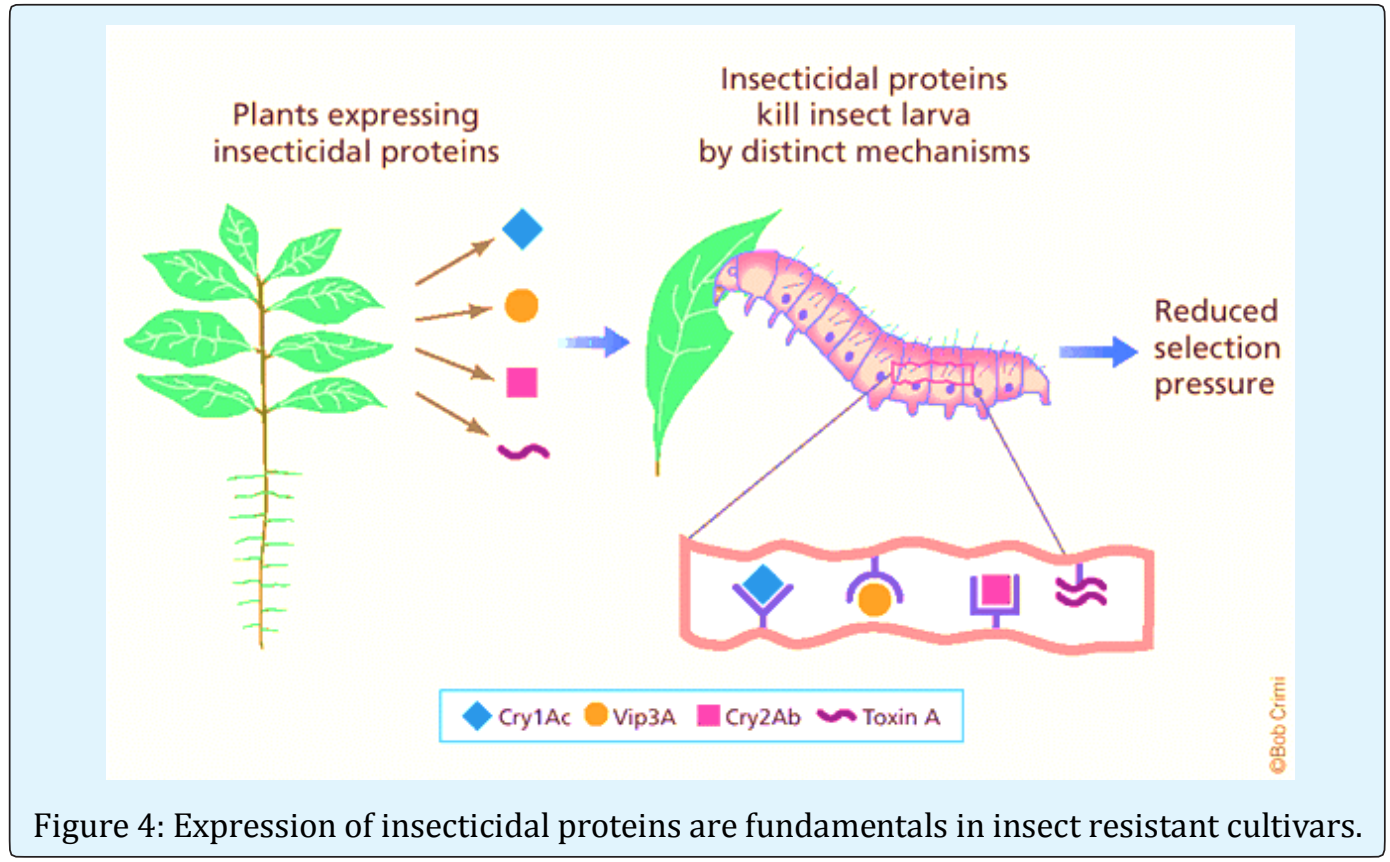

Javed MW, et al. Dynamicity of Plant-Insect Interaction, Defense 


\section{Open Access Journal of Agricultural Research}

This protein reveals important systems for defences, i.e., in basal and hormonal initiated immune systems usually for microbes and pathogenic resistance in plants. PAD4 is also contributing for salicylic acid integrity and production signallings via SA pathways [19].

\section{Plants and Mutualism Interrelationship}

Mutualistic type of relations or connections are dependent on the determination of insects and plants collective affiliations with huge limits of cooperation and coordinating actions at both physical and biological perceptions with greater cell and molecular replies within the plants and other production organisms [16]. To defeat efficiently the coming pathogens and insect pests; and to accomplish the beneficial microbial fauna, plants have developed broader and comprehensive mechanics. Such plants interact and possess the capability to perceive the living organism actions and reactions for plant own benefits with different pathways companionships [21].

\section{Plant Interactions in Ecological Perspective}

A number of biotic and abiotic parameters in the environment effects plant commitment with the called or uncalled guests of Insecta or microbial origin at trophic and community aspects. Often a self-induced stress may be there as extraneous spray of jasmonates cause prohibitions to $H$. zea with associated enhanced trichomes [22].
Some modal plant items such as Arabidopsis, although not much effectively describing the ecological relations of plants from Brassicaceae plant family but are contributively work for their assistive role in plant alliance and conjunctions. Nicotiana attenuata in nonbrassica plants serve for good molecular ecological appreciations [23].

\section{Plant Interactions in Molecular Perspective}

Plants are engaging themselves for a variety of individuals from harmful (pests) to beneficial (rhizobacteria) with wider ranges. Plants try to be on safer side by early considerations of invader mechanizations such as PAMPs, normally called as pathogen associated molecular patterns, helping a lot to deny the pathogen attacks $[21,24]$.

Signalling new transductions of transcripts of genes PR-pathogenesis related proteins, PIN-proteinase inhibitors, LOX-lipoxygenase, PAL-phenyl ammonia lyase; and biochemically whitefly modulated defense pathways in modal plant tomato Lycopersicon esculentum comprising Jasmonic Acid/JA and Salicylic Acid/SA cascades have been studied by the author and a simplified version has been struggled to be maintained in both ISRInduced Systemic Resistance and/or SAR-Systemic Acquired Resistance (Figure 5).

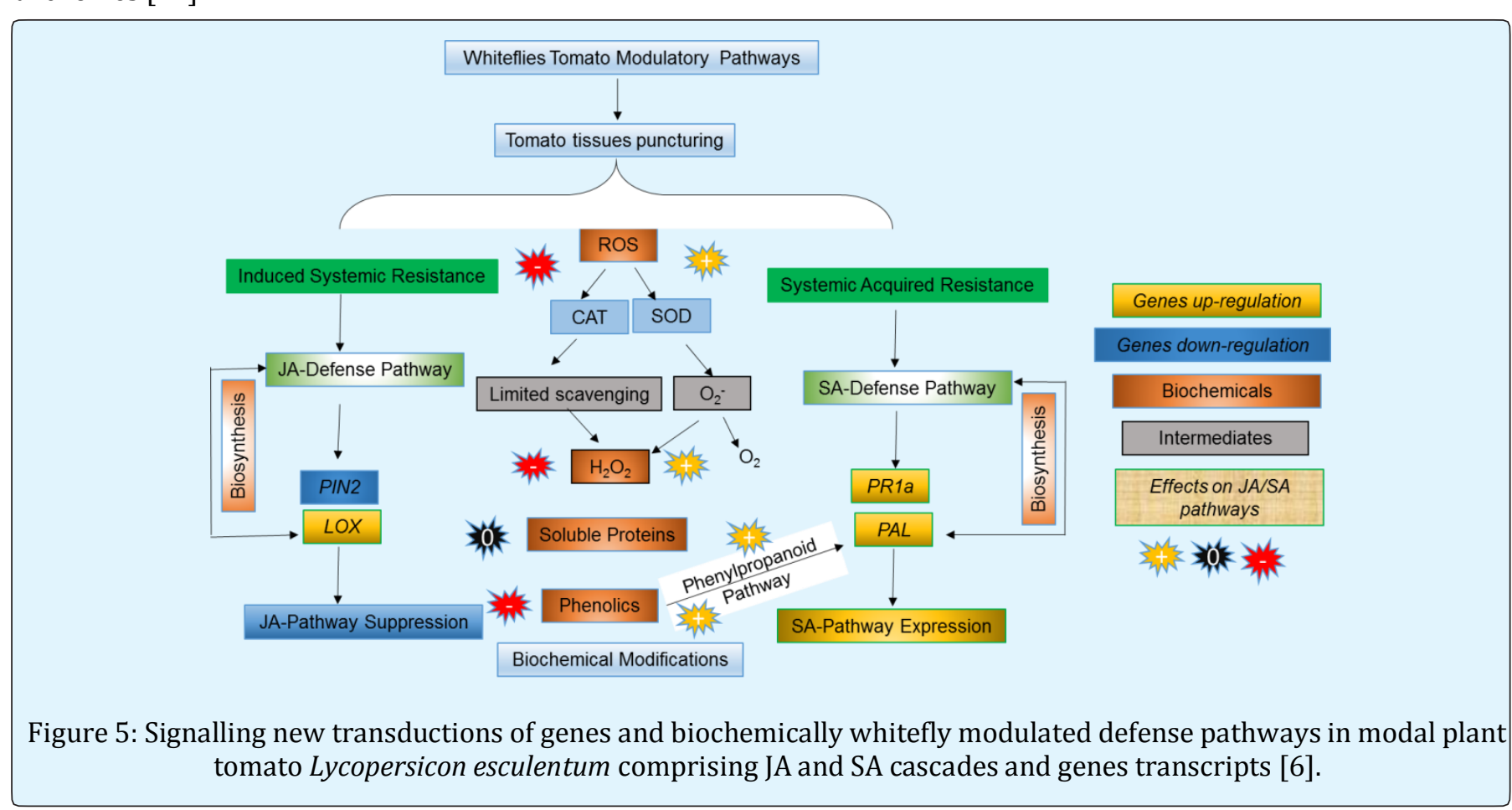




\section{Open Access Journal of Agricultural Research}

If this first defensive manner is appeared to be failed or overcome by the attacking agent, in this case, the plant may attain a specific kind of proteins, the R-proteins leading a secondary line of defensive capabilities. This Rprotein causes effectors stimulated (triggered) immunity in some plants. Lipoxygenase (LOX) enzymatic productions with different pathogenic relations seemed to be lessened in the silicon-applied tomato cropping systems, are worthy at molecular stage $[24,25]$. Induced resistance based defense genes response for suppression of Helicoverpa armigera Hubner (Lepidoptera: Noctuidae) via plant regulatory strategies in tomato has also been studied by the author [26].

\section{Conclusion}

Insects and plants are pivotal to global agrarian fauna and flora respectively. Both have dynamic interaction, defense systems and applied key-prospects for their survival and co-existence. They are interacting at multiple levels, externally showing no visible tug of war, but internally a number of defensive genes like PR, LOX, PIN, PALetc; and physiological factors like $\mathrm{H}_{2} \mathrm{O}_{2}$ and SOD, NADPH are underway. Additively, these genes and physiochemicals are further triggering SA/JA signalling pathways (e.g., SAR/ISR) to favor or harm either plants or insects in on-going interactive self-existence/survival stage. Henceforth, there will be win of the stronger contestant making itself more perpetuating. Concisely, the interaction dynamics in both living beings is not simple but accounting a number of aspects comprising internal signallings, ecological contributions and definitely molecular prospects.

\section{References}

1. Hancock RD, Hogenhout S, Foyer CH (2015) Mechanisms of plant-insect interaction. J Expt Bot 66(2): 421-424.

2. Pieterse CM, Dicke M (2007) Plant interactions with microbes and insects: From molecular mechanisms to ecology. Trends Plant Sci 12(12): 564-569.

3. Mescher MC, De Moraes CM (2015) The role of plant sensory perception in plant-animal interactions. J Expt Bot 66(2): 425-433.

4. Zebelo SA, Maffei ME (2015) Role of early signalling events in plant-insect interactions. J Extp Bot 66(2): 435-448.
5. Javed MW, Ahmad JN, Ahmad SJN, Hussain M, Hussain D, et al. (2018) Inscribing new genes and biochemical defense whiteflies modulatory signalling pathways in emerging modal plant tomato Lycopersicon esculentum Mill. International Conference on Plant Sciences 15-17 November, Paris, France.

6. Javed MW (2016) Study on induced resistance based defense genes expression to control consequential insect pests of tomato (Lycopersicon esculentum). Department of Entomology, University of Agriculture Faisalabad.

7. Bruce TJ (2015) Interplay between insects and plants: Dynamic and complex interactions that have coevolved over millions of years but act in milliseconds. J Expt Bot 66(2): 455-465.

8. Harvey JA, van Dam NM, Raaijmakers CE, Bullock JM, Gols R (2011) Tri-trophic effects of inter-and intrapopulation variation in defence chemistry of wild cabbage (Brassica oleracea). Oecologia 166(2): 421431.

9. Stam JM, Kroes A, Li Y, Gols R, van Loon JJ, et al. (2014) Plant interactions with multiple insect herbivores: from community to genes. Plant Biol 65: 689-713.

10. Husain D, Saleem M, Javed MW, Jafir M, Ashfaq M, et al. (2016) Soraj mukhi k nuqsandeh kery ar unka tadaruk. Zarai Digest 16: 15-17.

11. Javed MW, Husain D, Saleem M (2014) Sunflower Insect Pests Control (Special Reference to Planting Dates). LAP Lambert Academic Publishing, Germany.

12. Javed MW, Naveed A, Hussain D, Ahmad JN, Saleem M, et al. (2018) First Record, Prevalent Hosts, Biological and Managing Attributes of False Chinch Bug (Hemiptera: Lygaeidae) Injuring Helianthus annuus, Brassica and Chenopodium from Punjab, Pakistan. Entomology, Ornithology \& Herpetology 7(1): 208.

13. Poelman EH, Broekgaarden C, Van Loon JJ, Dicke M (2008) Early season herbivore differentially affects plant defence responses to subsequently colonizing herbivores and their abundance in the field. Mol Ecol 17(14): 3352-3365.

14. Kerchev PI, Fenton B, Foyer CH, Hancock RD (2012) Plant responses to insect herbivory: Interactions between photosynthesis, reactive oxygen species and 


\section{Open Access Journal of Agricultural Research}

hormonal signalling pathways. Plant Cell Environ 35(2): 441-453.

15. Akbar N, Ishfaq M, Iqbal A, Javed MW, Aslam A, et al. (2016) Optimization of Wheat (Triticum aestivum L.) Yield Relativities via Varying Levels of Potassium and Planting Geometry. Report and Opinion 8(5): 35-38.

16. Harrison MJ (2005) Signaling in the arbuscular mycorrhizal symbiosis. Annu Rev Microbiol 59: 1942.

17. Kessler D, Baldwin IT (2007) Making sense of nectar scents: The effects of nectar secondary metabolites on floral visitors of Nicotiana attenuata. Plant J 49(5): 840-854.

18. Ahmad JN, Jafir M, Ahmad SJN, Javed MW, Majeed D, et al. (2017) Quality characterization of 40 abiotic stress tolerant CIMMYT synthetic hexaploid wheat (Triticum aestivum) lines with respect to pest resistance. Academic Journal of Entomology 10(2): 19-24.

19. Louis J, Shah J (2015) Plant defence against aphids: The PAD4 signalling nexus. J Expt Bot 66(2): 449-454.

20. Puthoff DP, Holzer FM, Perring TM, Walling LL (2010) Tomato pathogenesis-related protein genes are expressed in response to Trialeurodes vaporariorum and Bemisia tabaci biotype B feeding. J Chem Ecol 36(11): 1271-1285.
21. Jones JD, Dangl JL (2006) The plant immune system. Nature 444(7117): 323-329.

22. Tian D, Peiffer M, De Moraes CM, Felton GW (2014) Roles of ethylene and jasmonic acid in systemic induced defense in tomato (Solanum lycopersicum) against Helicoverpa zea. Planta 239(3): 577-589.

23. Kessler A, Halitschke R, Baldwin IT (2004) Silencing the jasmonate cascade: Induced plant defenses and insect populations. Science 305(5684): 665-668.

24. Chisholm ST, Coaker G, Day B, Staskawicz BJ (2006) Host-microbe interactions: Shaping the evolution of the plant immune response. Cell 124(4): 803-814.

25. Kurabachew H, Wydra K (2014) Induction of systemic resistance and defense-related enzymes after elicitation of resistance by rhizobacteria and silicon application against Ralstonia solanacearum in tomato (Solanum lycopersicum). Crop Prot 57: 1-7.

26. Javed MW, Ahmad JN, Ahmad SJN, Rasool S, Naveed A, et al. (2018) Induced resistance based defense genes response for suppression of Helicoverpa armigera Hubner (Lepidoptera: Noctuidae) via plant regulatory strategies in tomato. The 10th Scandinavian Plant Physiology Society PhD Student Conference Københavns Universitet, University of Copen 